\title{
Dampak Komunitas Belajar Terhadap Minat Belajar Mahasiswa S1 Program Studi Pendidikan Biologi Stkip Muhammadiyah Sorong
}

\author{
Muhammad Ramli dan Sirojjuddin \\ Program Studi Pendidikan Biologi STKIP Muhammadiyah Sorong \\ Email: sirojjuddin.biologi3@gmail.com
}

\begin{abstract}
The purpose of this study was to determine the effect of self-learning communities on Students motivation to learn. The method used is an experimental method that is assessed quantitatively and qualitatively, the research conducted at the Biology Education Departemen, STKIP Muhammadiyah Sorong on May 5 to June 10, 2014, the population of 165 Students and 40 Students sample size. The instrument used was a questionnaire previously tested the reliability and validity of the results are reliable and valid. The results showed that all questionnaire data were normally distributed and sample all homogeneous. Results of two sample paired t-test (paired samples) Semester I $\left(t_{\text {hitung }}=1.041<t_{\text {tabel }}=2.13\right)$, Semester III $\left(t_{\text {hitung }}=4.815>\right.$ $\left.t_{\text {tabel }}=2.20\right)$, Semester $V\left(t_{\text {hitung }}=1.290<t_{\text {tabe }} l=2.31\right)$, and the One-Way ANOVA test between departments $\left(F_{\text {hitung }}=1.834<F_{\text {tabel }}=3.276\right)$, and the One-Way ANOVA test between levels $\left(F_{\text {hitung }}=0.571<F_{\text {tabel }}=\right.$ 3.276), so there are differences in motivation to learn in semester III before and after treatment but there was not difference in the motivation to learn on semester I and level $V$ before and after treatment, and there is no major difference between learning motivation and between levels. However, the fact of the faculty questionnaire, interview and documentation showing that autonomous learning communities can changes positive motivation towards learning in the lecture.
\end{abstract}

Key words: community, self-contained, Biology Education Departemen,STKIP Muhammadiyah Sorong,

\begin{abstract}
Abstrak: Tujuan penelitian ini untuk mengetahui dampak komunitas belajar mandiri terhadap motivasi belajar mahasiswa. Metode yang digunakan adalah metode eksperimen yang dikaji secara kuantitatif dan kualitatif, penelitian dilaksanakan di Program Studi Pendidikan Biologi STKIP Muhammadiyah Sorong pada bulan september-November 2017, dengan jumlah populasi 165 mahasiswa dan jumlah sampel 40 mahasiswa. Instrumen yang digunakan adalah angket yang sebelumnya diuji reliabilitas dan validitas yang hasilnya reliabel dan valid. Hasil penelitian diperoleh bahwa data angket semua berdistribusi normal dan sampel semua homogen. Hasil uji t two sampel berpasangan (paired sampel) semester I $\left(\mathrm{t}_{\text {hitung }}=1.041<\mathrm{t}_{\text {tabel }}=2.13\right)$, emester III $\left(\mathrm{t}_{\text {hitung }}=4.815\right\rangle$ $\left.\mathrm{t}_{\text {tabel }}=2.20\right)$, semester $\mathrm{V}\left(\mathrm{t}_{\text {hitung }}=1.290<\mathrm{t}_{\text {tabe }} \mathrm{l}=2.31\right)$, dan uji One-Way ANOVA antar jurusan $\left(\mathrm{F}_{\text {hitung }}\right.$ $\left.=1.834<\mathrm{F}_{\text {tabel }}=3.276\right)$, dan uji One-Way ANOVA antar semesteran $\left(\mathrm{F}_{\text {hitung }}=0.571<\mathrm{F}_{\text {tabel }}=3.276\right)$, sehingga ada perbedaan motivasi belajar pada semester III sebelum dan sesudah perlakuan tetapi tidak ada perbedaan motivasi belajar semester I dan V sebelum dan sesudah perlakuan, serta tidak ada perbedaan motivasi belajar antar semester. Namun, fakta dari angket dosen, wawancara dan dokumentasi menunjukan bahwa komunitas belajar mandiri dapat merubaah ke arah positif motivasi belajar dalam perkuliahan.
\end{abstract}

Kata kunci: komunitas, mandiri, Pendidikan Biologi, STKIP Muhammadiyah Sorong

\section{PENDAHULUAN}

Pentingnya pengembangan keterampilan berpikir kreatif dituangkan dalam tujuan pendidikan nasional yaitu mengembangkan potensi peserta didik agar menjadi manusia yang bertakwa kepada Tuhan yang Maha Esa, berakhlak mulia, sehat, berilmu, cakap, kreatif, mandiri dan menjadi warga negara yang demokratis serta bertanggung jawab ${ }^{[i]}$. Kemampuan berpikir kreatif yang dimiliki oleh lulusan pendidikan dasar sampai perguruan tinggi masih rendah. Keterampilan berpikir ini belum ditangani dengan baik. Karena itu, penanganan keterampilan berpikir kreatif sangat penting diintegrasikan dalam setiap mata kuliah ${ }^{[i i]}$.

Belajar adalah suatu proses dimana dalam proses tersebut terjadi interaksi, baik antar individu maupun dengan lingkungannya sehingga membentuk hasil belajar ${ }^{[\text {iii }]}$. Karena berinteraksi dapat 
mempengaruhi pencapaian akademik mahasiswa ${ }^{[i v]}$. Salah satu hambatan sering dialami dalam mengajar adalah soal waktu. Seringkali seseorang mengajar tidak dapat mengendalikan waktu. Akibatnya bisa terjadi bahan pelajaran sudah selesai, namun waktu masih panjang, atau sebaliknya waktu sudah habis, tetapi bahan belum tuntas. Hal ini membawa pengaruh terhadap proses belajar mengajar yang dilaksanakan ${ }^{[\mathrm{v}]}$.

Proses belajar dapat juga melalui pembentukan kelompok belajar yang menuntut mahasiswa untuk belajar mandiri. Yaitu, mahasiswa menciptakan suatu diskusi yang berkualitas karena kualitas diskusi mempengaruhi semester kesuksesan belajar mahasiswa ${ }^{[v i]}$.

Akan tetapi, pada kenyataannya selama ini mahasiswa belum membentuk komunitas belajar mandiri. Salah satunya adalah mahasiswa di Program Studi Pendidikan Biologi STKIP Muhammadiyah Sorong. Menurut penuturan Sekretaris Biro Kemahasiswaan Bapak Solehun, di Program Studi Pendidikan Biologi STKIP Muhammadiyah Sorong belum terbentuk komunitas belajar mandiri, mahasiswa selama ini belajar di ruangan pada setiap program studi. Untuk itu perlu dibentuk komunitas belajar mandiri. Komunitas belajar ini bertujuan untuk meningkatkan motivasi belajar mahasiswa. Pembentukan komunitas tersebut juga perlu dilakukan riset untuk mengetahui dampak terhadap motivasi belajar dalam perkuliahan. Selain itu, penelitian tentang komunitas belajar mandiri mahasiswa belum pernah dilakukan di Sorong.

\section{METODE PENELITIAN}

Penelitian ini merupakan jenis penelitian eksperimen. Penelitian ini dikaji secara kualitatif dan kuantitatif. Populasi dalam penelitian ini adalah seluruh mahasiswa Program Studi Pendidikan Biologi sebanyak 165 mahasiswa tahun akademik 2017/2018. Sampel dalam penelitian terdiri dari 40 mahasiswa. Materi penelitian ini adalah pembentukan komunitas belajar mandiri. Instrumen yang digunakan yakni angket, obsevasi, wawancara, dan dokumentasi. Penelitian ini dilaksanakan di STKIP Muhammadiyah Sorong. Aktivitas penelitian ini secara keseluruhan dilaksanakan selama tiga bulan, sejak bulan September hingga November 2017.

Analisis hasil penelitian meliputi beberapa uji yakni uji instrumen (uji reliabilitas dan uji validitas), uji sampel (uji homogenitas), uji data (uji normalitas) serta uji hipotesis (uji parametric (uji $t$ two sampel berpasangan (paired sample) dan uji One-Way ANOVA. Pengelolaan data hasil penelitian mengunakan aplikasi SPSS 17.

\section{PEMBAHASAN}

\subsection{Deskrisi data penelitian}

Hasil uji instrumen angket awal menunjukkan rata-rata skor item pernyataan antara 3,1 sampai 4,2. Skor tertinggi berada pada item pernyataan nomor 2 sedangkan skor terendah pada item pernyataan nomor 9. Hasil ditunjukkan pada Gambar. 3.1.

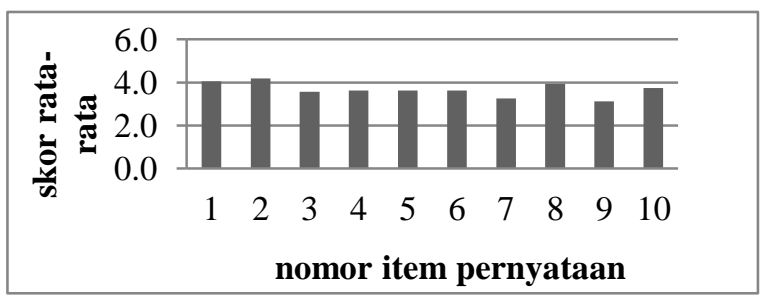

Gambar 3.1 Grafik data hasil uji prasyarat instrumen angket

Hasil angket awal akhir 18 mahasiswa semester I diperoleh skor rata-rata antara 3,06 hingga 4,72 Skor tertinggi berada pada item pernyataan nomor 1 , sedangkan skor terendah pada item pernyataan nomor 6 dan 8. Hasil angket awal akhir 12 mahasiswa semester III diperoleh skor rata-rata 3,25 hingga 4,83. Skor tertinggi berada pada item pernyataan nomor 1 dan terendah pada item pernyataan nomor 6 dan 8 . Hasil angket awal akhir 10 mahasiswa semester V diperoleh skor rata-rata 2,89 hingga 4,70. Skor tertinggi berada pada item pernyataan nomor 1 dan terendah pada item pernyataan nomor 6. Hasil ditunjukkan pada Gambar. 3.3. 

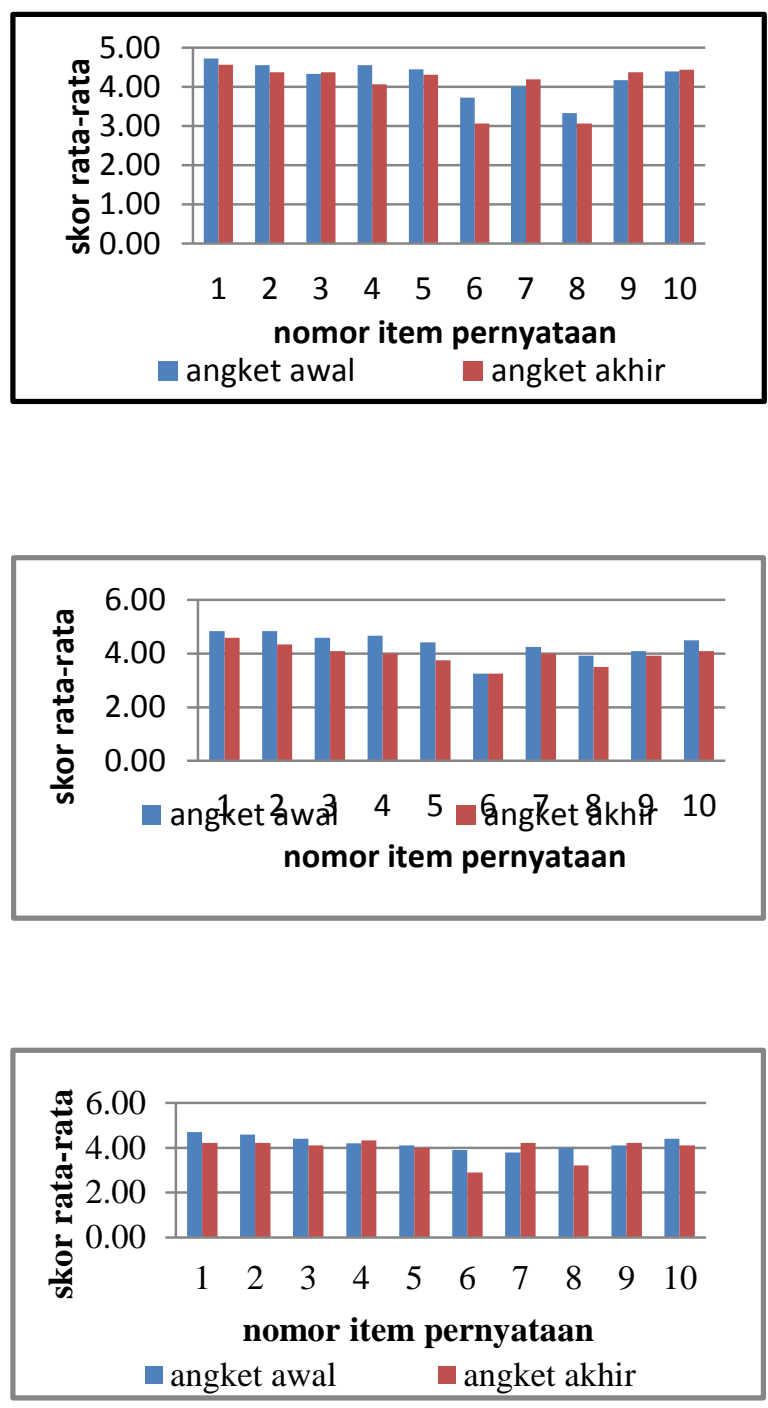

Gambar 3.2 Grafik Data Hasil Angket Awal Akhir Semester I,II dan III.

Hasil angket dosen yang disebarkan pada hari Rabu, 04 Oktober 2017 kepada lima dosen bagian Kemahasiswaan perwakilan dari respon dosen Program Studi Pendidikan Biologi diperoleh data seperti ditampilkan pada Tabel 3.1. Tabel 3.1 menunjukkan bahwa dari 8 item pernyataan memperoleh skor rata-rata antara 4,00 hingga 4,25. Skor tertinggi pada nomor 3 , terendah pada nomor 5 dan 6.

Tabel 3.1 Data Hasil Angket Dosen

\begin{tabular}{|c|c|c|c|c|c|c|c|c|}
\hline \multirow{2}{*}{ Nama } & \multicolumn{8}{|c|}{ Nomor Pernyataan } \\
\hline & 1 & 2 & 3 & 4 & 5 & 6 & 7 & 8 \\
\hline Responden 1 & 4 & 4 & 4 & 4 & 4 & 4 & 4 & 4 \\
\hline Responden 2 & 4 & 4 & 4 & 4 & 4 & 4 & 4 & 4 \\
\hline Responden 3 & 4 & 4 & 4 & 4 & 4 & 4 & 4 & 4 \\
\hline Responden 4 & 5 & 5 & 5 & 5 & 4 & 4 & 5 & 5 \\
\hline Responden 5 & 4 & 4 & & 4 & 4 & 4 & 4 & 4 \\
\hline JUMLAH & 21 & 21 & 17 & 21 & 20 & 20 & 21 & 21 \\
\hline $\begin{array}{l}\text { RATA- } \\
\text { RATA }\end{array}$ & 4,20 & 4,20 & 4,25 & 4,20 & 4,00 & 4,00 & 4,20 & 4,20 \\
\hline
\end{tabular}




\begin{tabular}{ccccccccc}
\hline MIN & 4 & 4 & 4 & 4 & 4 & 4 & 4 & 4 \\
\hline MAX & 5 & 5 & 5 & 5 & 4 & 4 & 5 & 5 \\
\hline
\end{tabular}

Hasil observasi diperoleh skor rata-rata skor rata-rata antara 3,85 hingga 5,00. Skor tertinggi berada pada item pernyataan nomor 8 , sedangkan skor terendah pada item pernyataan nomor 1 . Data hasil angket dosen secara lengkap ditampilkan pada Tabel 3.2.

Tabel 3.2 Data Hasil Observasi Mahasiswa

\begin{tabular}{lcccccccc}
\hline \multirow{2}{*}{ Jurusan/semester } & \multicolumn{7}{c}{ Nomor Item Pengamatan } \\
\cline { 2 - 9 } & $\mathbf{1}$ & $\mathbf{2}$ & $\mathbf{3}$ & $\mathbf{4}$ & $\mathbf{5}$ & $\mathbf{6}$ & $\mathbf{7}$ & $\mathbf{8}$ \\
\hline TBP & 3.67 & 4.00 & 3.67 & 4.00 & 4.00 & 4.00 & 4.00 & 4.00 \\
\hline TPI & 4.00 & 4.00 & 4.00 & 4.00 & 4.00 & 4.00 & 4.00 & 4.00 \\
\hline MPP & 3.67 & 4.00 & 4.00 & 4.00 & 3.67 & 4.00 & 4.00 & 4.00 \\
\hline Semester 1 & 4.00 & 4.00 & 4.00 & 4.00 & 4.00 & 4.00 & 4.00 & 4.00 \\
\hline Semester 2 & 3.67 & 4.00 & 3.67 & 4.00 & 4.00 & 4.00 & 4.00 & 4.00 \\
\hline Semester 3 & 3.67 & 4.00 & 4.00 & 4.00 & 3.67 & 4.00 & 4.00 & 4.00 \\
\hline
\end{tabular}

Tabel 3.3 Data Hasil Pengujian

\begin{tabular}{|c|c|c|c|c|}
\hline Uji & Perumusan & $\begin{array}{c}\text { Hasil } \\
\text { hitung }\end{array}$ & $\begin{array}{l}\text { Hasil } \\
\text { tabel }\end{array}$ & Keputusan \\
\hline Homogenitas B1 dan B 3 & Levene & 0,487 & 0,05 & Homogen \\
\hline Homogenitas B1 dan B5 & Levene & 0,685 & 0,05 & Homogen \\
\hline Homogenitas B3 dan B5 & Levene & 0,756 & 0,05 & Homogen \\
\hline $\begin{array}{l}\text { Normalitas } \\
\text { akhir }\end{array}$ & Shapiro-Wilk & $\begin{array}{l}0,444 \\
0,179\end{array}$ & 0,05 & Normal; Normal \\
\hline Normalitas B3 awal; akhir & Shapiro-Wilk & $\begin{array}{l}0,070 \\
0,226\end{array}$ & 0,05 & Normal; Normal \\
\hline Normalitas B5 awal; akhir & Shapiro-Wilk & $\begin{array}{l}0,430 \\
0,943\end{array}$ & 0,05 & Normal; Normal \\
\hline Hipotesis B1 & $\begin{array}{l}\text { t two sampel } \\
\text { berpasangan }\end{array}$ & 1,041 & 2,13 & $\mathrm{H}_{0}$ diterima \\
\hline Hipotesis B3 & $\begin{array}{l}\text { t two sampel } \\
\text { berpasangan }\end{array}$ & 4,815 & 2,20 & $\mathrm{H}_{1}$ diterima \\
\hline Hipotesis B5 & $\begin{array}{l}\text { t two sampel } \\
\text { berpasangan }\end{array}$ & 1,290 & 2,31 & $\mathrm{H}_{0}$ diterima \\
\hline Hipotesis B1, B3 dan B5 & One Way Anova & 0,571 & 3,276 & $\mathrm{H}_{0}$ diterima \\
\hline
\end{tabular}

\subsection{Pembahasan Uji Prasyarat Instrumen}

Hasil analisis instrumen angket menunjukkan bahwa uji reliabilitas menunjukkan bahwa angket reliabel, serta uji validitas yang menunjukkan bahwa semua pernyataan angket valid sehingga dapat digunakan sebagai instrumen penelitian.

\subsection{Pembahasan Uji Prasyarat Analisis}

Hasil uji sampel mahasiswa antar jurusan diperoleh bahwa sampel antar semester diperoleh bahwa antar semester I terhadap III, I terhadap V serta III terhadap V adalah homogen. Untuk jurusan dan semester homogen karena mahasiswa berada di lingkungan kampus yang sama serta sama-sama mengikuti komunitas belajar mandiri. Uji normalitas menyatakan bahwa semua data berdistribusi normal, maka uji hipotesis yang digunakan adalah uji parametrik yaitu uji t two sampel berpasangan (pired sample). Tetapi, uji hipotesis juga dipengaruhi juga dari hasil uji homogenitas sampel. Berdasarkan hasil uji sampel diperoleh fakta bahwa semua sampel adalah homogen sehingga menggunakan uji One Way ANOVA. 


\subsection{Pembahasan Penelitian Mahasiswa Semester I}

Hasil Penelitian Mahasiswa Semester I diperoleh bahwa perhitungan ststistik hipotesis yang diterima yakni $\mathrm{H}_{0}$ (tidak ada perbedaan efek motivasi belajar sebelum dan sesudah dilakukan pembentukan komunitas belajar mandiri pada Mahasiswa Semester I). Hasil perhitungan tersebut menunjukkan Mahasiswa Semester I sebelum dan sesudah diberlakukan komunitas belajar mandiri tidak mengalami perbedaan motivasi. Hal ini dikarenakan Mahasiswa cenderung tidak mengikuti kegiatan dengan baik karena mengobrol sama temannya dan bermain HP pada saat berada di komunitas belajar mandiri yang dibuktikan dengan hasil dokumentasi. Selain itu, Mahasiswa belum mengetahui maksud dan tujuan dari komunitas belajar mandiri dikarenakan komunitas belajar mandiri ini baru pertama kali dilaksanakan yang dibuktikan dengan hasil wawancara. Selain itu juga dibuktikan dengan berkurangnya Mahasiswa yang mengikuti komunitas belajar mandiri, yang awalnya berjumlah 18 menjadi 16 Mahasiswa. Akan tetapi menurut dosen, bahwa Mahasiswa lebih termotivasi dalam belajarnya setelah mengikuti komunitas belajar mandiri. Hal ini dibuktikan dengan hasil angket dosen item nomor 3 yang nilai skornya 4,25 yang lebih tinggi dibandingkan skor item yang lainnya. Selain itu juga mengikuti kegiatan dengan baik yang dibuktikan oleh hasil observasi pada item nomor 4 memperoleh skornya 4,00 .

\subsection{Pembahasan Penelitian Mahasiswa Semester III}

Hasil Penelitian Mahasiswa semester III diperoleh bahwa perhitungan ststistik hipotesis yang diterima yakni $\mathrm{H}_{1}$ (ada perbedaan efek motivasi belajar sebelum dan sesudah dilakukan pembentukan komunitas belajar mandiri pada Mahasiswa semester III). Hasil perhitungan tersebut menunjukkan Mahasiswa semester II sebelum dan sesudah diberlakukan komunitas belajar mandiri mengalami perbedaan motivasi. Ini dibuktikan dari hasil angket yang nunjukan pada item nomor 1, 2, 3, 4, 5, 7, 8, 9 dan 10 mengalami perubahan skor. Ini disebabkan oleh letak ruang kegiatan yang kurang mendukung sehingga membuat mahasiswa kebingungan serta jenuh dalam mengikuti kegiatan komunitas belajar mandiri yang dibuktikan oleh hasil dokumentasi. Akan tetapi menurut dosen, bahwa hasil belajar mahasiswa lebih baik setelah mengikuti komunitas belajar mandiri yang ditunjukan hasil angket dosen pada item nomor 8 dengan memperoleh hasil skor 4,20 yang berarti jawaban dosen berkisar di antara jawaban "setuju" hingga "sangat setuju" serta didukung oleh hasil observasi pada item pengamatan nomor 6 memperoleh skor 4,00 jawaban berkisar di pilihan "sedang" yang menyatakan bahwa Mahasiswa berinteraksi secara aktif pada saat kegiatan.

\subsection{Pembahasan Penelitian Mahasiswa Semester V}

Hasil Penelitian Mahasiswa Semester V diperoleh bahwa perhitungan ststistik hipotesis yang diterima yakni $\mathrm{H}_{0}$ (tidak ada perbedaan efek motivasi belajar sebelum dan sesudah dilakukan pembentukan komunitas belajar mandiri pada Mahasiswa Semester III). Hasil perhitungan tersebut menunjukkan Mahasiswa Semester V sebelum dan sesudah diberlakukan komunitas belajar mandiri tidak mengalami perbedaan motivasi. Hal ini dibuktikan oleh hasil dokumentasi bahwa Mahasiswa kurang antusias dalam mengikuti komunitas belajar mandiri. Tidak adanya perbedaan ini disebabkan Mahasiswa baru mengenal komunitas belajar mandiri sehingga Mahasiswa belum mengerti maksud dan tujuan dari komunitas belajar mandiri. Hal ini disebabkan komunitas belajar mandiri baru dilakukan yang dibuktikan dengan hasil wawancara Mahasiswa. Selain itu dalam komunitas belajar mandiri Mahasiswa Semester V masih rendah kepedulian dengan Mahasiswa lain, dibuktikan oleh hasil observasi pada item pengamatan nomor 1 dengan memperoleh skor 3,67 yang berarti jawaban berkiar "sedang" hingga "baik". Akan tetapi menurut dosen, motivasi Mahasiswa lebih baik setelah mengikuti komunitas belajar mandiri. Hal ini dibuktikan dengan hasil angket dosen pada item pernyataan nomor 3 dengan memperoleh skor 4,25 yang berarti jawaban berkisar antara "setuju" dan "sangat setuju".

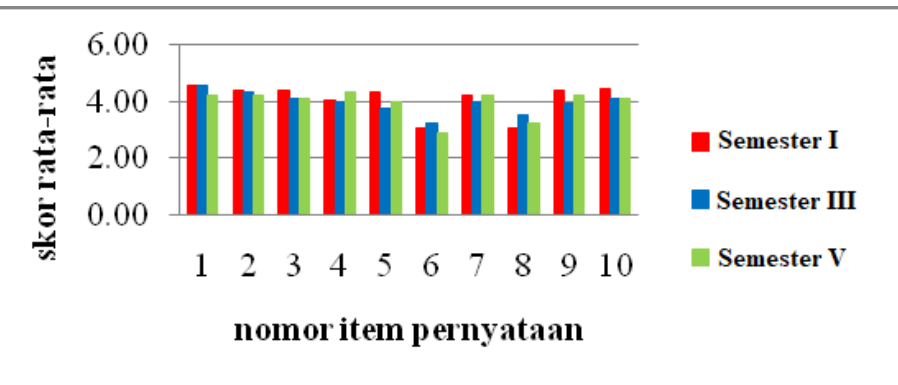


Gambar 3. 4 Grafik perbandingan hasil angket akhir antar semester.

\section{KESIMPULAN DAN SARAN}

Hasil dari penelitian komunitas belajar mandiri menurut pengujian secara statistic menunjukan adanya perbedaan motivasi belajar pada semester semester III serta tidak adanya perbedaan motivasi belajar pada semester I dan V. Sedangkan menurut angket yang disebarkan ke dosen serta hasil wawancara beberapa mahasiswa dan dosen menunjukan bahwa komunitas belajar mandiri membantu pada saat proses belajar di dalam perkuliahan. Sehingga secara keseluruhan dapat disimpulkan bahwa pembentukan komunitas belajar mandiri tidak berefek langsung terhadap motivasi belajar mahasiswa pada saat penelitian, akan tetapi berefek pada saat perkuliahan.

Berdasarkan hasil penelitian ini, maka disarankan perlu dibentuknya komunitas belajar mandiri di Perguruan Tinggi sebagai cara belajar efektif agar mahasiswa dapat memanfaatkan waktu di luar kegiatan kampus dengan baik.

\section{DAFTAR PUSTAKA}

Rofi'uddin, A. 2000. Model Pendidikan Berpikir Kritis Kreatif untuk Siswa Sekolah Dasar. Majalah Bahasa dan Seni 1.

Aunurahman. 2009. Belajar dan Pembelajaran. Bandung: Alfabeta.

Doljanac, R.F. 1994. Using motivational factors and learning strategies to predict academic success. Doctoral Dissertations, The University of Michigan, 1994. Dissertation Abstracts International 56, (01A) : 0142.

Ali, M. 2008. Guru Dalam Proses Belajar Mengajar. Bandung; Sinar Baru Algensindo.

Nieminen J, Sauri P, dan Lonka K. 2006. On The Relationship Between Group Functioning And Study Success In Problem-Based Learning. Medical Education. 